\title{
Tinkering Toward a National Identification System: An Experiment on Policy Attitudes
}

\author{
Valentina Bali
}

\begin{abstract}
The REAL ID Act was passed in 2005 by Congress in part to address preoccupations with breaches to homeland security after the 9/11 attacks. The Act requires states to introduce more standardized state driver's licenses by 2008. The goal of this paper is to understand citizens' opinions in the area of personal identification and how these opinions may be shaped by alternative framings of the issue. Using survey responses from Michigan residents provides evidence of the following: (i) a majority of the Michigan public supports the current reforms in identification; however, a majority is not willing to incur larger costs or delays; (ii) framing the issue around immigration can generate as much support as framing the issue around terrorism; however, a more balanced discourse can dampen support; and (iii) partisan and ideological leanings moderately structure support for identification reforms. Overall the findings suggest a comfortable margin for reforms around personal identification if public safeguarding interpretations can predominate.
\end{abstract}

KEY WORDS: personal identification, framing experiment, public opinion, terrorism, immigration

\section{Introduction}

One of the consequences of $9 / 11$ and the breach to homeland security has been a renewed interest from the national government in improving personal identification systems in the United States. Investigations after the 9/11 attacks revealed that 18 of the 19 executors had been issued U.S. identification cards, with two of these being fraudulent (Secretary Chertoff, 2007). The September 11th Commission investigating the attacks extended a recommendation for improved identification stating, "secure identification should start in the United States" (The 9-11 Commission Report, 2004, p. 390). In part as a result of these heightened concerns with security, Congress passed the REAL ID Act in May of 2005, seeking more secure and federal standards for state-issued driver's licenses by $2008 .{ }^{1}$ Responses to the Act were soon felt, with preoccupations with privacy, costs, and feasibility soon arising from many states and interested associations. Despite these, the federal government has strongly insisted on the move toward increased verifiability and standardization in the area of personal identification, in part as a result of the continuing security challenges and the general worldwide trends in hi-tech identification. However, the ultimate fate of 
this Act has not been settled. Congress changed party hands after the 2006 election and considerable noncompliance efforts are stemming from various states, events that may reshape its final implementation.

If any such reform is to fully take place and given the political elites' and the media's emergent debate around the subject of identification, it is critical to understand citizens' concerns around this issue. Citizens will be the direct recipients of the Act and potentially of some of its costs therefore state politicians may take notice of their preferences. This study examines citizens' opinions in the area of personal identification and how these opinions may be sensitive to alternative framings of the issue. To do so, a survey from Michigan residents in 2006 was undertaken. This kind of analysis provides a variety of advancements. First, the project contributes to our understanding of public opinion in a new and increasingly salient policy area for which there is scant previous research. Second, the questionnaire presents a careful experimental design that tests how various frames around the issue of identity cards, including a neutral frame and a balanced contested frame, can influence respondents' opinions on the issue. Finally, this research has broader implications for our understanding of what influences citizens' attitudes toward security-related reforms in general. Overall, the results suggest the public supports reforming the identification systems toward standardized IDs, as in the REAL ID Act, and even more so when public safeguarding considerations prevail. Partisan attachments do not strongly shape attitudes, but if costs, privacy concerns, or a lack of trust in the government balance the discourse the support may become more marginal.

\section{Controversies Around National IDs}

Setting up an explicit national ID card in the United States has been anathema for politicians for a long time, and in fact, any such efforts have been contrary to many common law countries. Although by some counts national ID systems are used by over a hundred countries worldwide, with most European, Asian, and African countries having such schemes, countries whose legal systems have stemmed from common law traditions have often rejected the concept of a national ID (Wadham, Gallagher, \& Chrolavicius, 2006, p. 11). In fact, Australia, New Zealand, Canada, and the United States have in the last decades rejected explicit efforts of introducing a national ID (Wadham et al., 2006, p. 26).

While the types of cards and their uses can vary, the objective of a national ID card is to provide a universal government-issued document that validates an individual's identity and that can then be used for purposes of identification in various functions (e.g., opening banking accounts, identification with law enforcement, voting, receiving federal benefits, or boarding an aircraft). In the United States the Social Security card and, more distinctly so, the states' driver's licenses and personal identification cards have acted as the effective identification cards. However, since the events of $9 / 11$ and its aftermath, the notion of reforming identity documents to achieve higher security gained traction in the U.S. Congress, resulting in the REAL ID Act of 2005, and inched its way into the public discourse. In the United Kingdom, 
similar concerns with security prompted the passage of the Identity Cards Act of 2006, which includes biometric identity cards for foreign nationals and national IDs starting in 2009 (Home Office, 2006).

At the core of a national ID debate, or any identification reform, is a clash between concerns with social order and concerns with civil liberties; or concerns with public safety and concerns with privacy. While a national ID card may improve public safety in the view of some by cutting down on an array of crimes, including now terrorism, for others it can also raise concerns regarding a whole range of privacy issues, such as the government's ability to track individuals and the increased exposure of personal information. To this inherent conflict between values we then need to add to the mix less abstract considerations such as costs and the feasibility of implementation. The debates on reforming existing IDs can trigger questions such as how will the costs of the reforms be borne: by the national government, the localities, or by citizens? Or, can the extant technology related to personal IDs (e.g., issuance, verification, and databasing) be reformed within short time frames without added security concerns?

In spite of the multiple concerns that can arise when considering a reform of identification systems the American public seems to be favorably disposed. For example, in terms of support for security-related reforms in general, poll data, and public opinion literature post 9/11 have suggested that Americans are willing to forego their civil liberties when national or personal securities are threatened. According to a 2006 Pew Research Center survey, a 46\% plurality of respondents is more concerned that the government has not gone far enough to protect the country as opposed to having gone too far in restricting civil liberties (Pew Research Center, 2006a). In terms of approval of specific identification reforms, immediately after $9 / 11$ support for a national ID card that had to be carried at all times to show to a police officer on request reached 70 percent; by 2002 the support settled down to 59 percent, though by 2006 such a proposal still elicited 56 percent of support (Pew Research Center, 2006a).

However, the levels of support for any such reform may evolve depending on the knowledge of citizens of the specifics of the reform, the framing that predominates at any point in time, and the costs involved, among others. In the case of the REAL ID Act, we might conjecture-because there are no national measures yet-that the public's knowledge about this Act is very low in which case approval levels may still evolve. In the case of proposals for a national ID, previous polls suggest support can vary depending on which purposes are emphasized through question wording. For example, a Newsweek poll immediately after 9/11 found 80-percent support for ID cards issued to every citizen "designed to be as tamperproof as possible" (Polling Report, 2001). This is in contrast to the 70 percent support obtained by the 2001 Pew Research Poll previously mentioned in which the proposed card is to be carried at all times and shown to a police officer. That is, when an ID-related question emphasizes the safety of the ID instead of possibly raising concerns with privacy and individual rights, support becomes higher. Finally, the British experience with revamping its identification system suggests a lessening of support for an ID reform as the details and costs of the program are unveiled, going 
from an estimated support level of 79 percent in 2003 when the national ID plan was first unveiled (Home Office, 2004), to 47 percent in 2006, when specific fees for the IDs were discussed (ICM Research, 2006).

In sum, despite a presupposed negative institutional bias, the American public may be at this time well inclined toward a more standardized identification system. But, as the public becomes more aware of the specific reforms entailed by the REAL ID Act, and as political elites, interested groups, and the media more actively debate them this backing may diminish.

\section{The REAL ID Act and Its Context}

Today, the most commonly used government identification in the United States, the state driver's license, provides the credentials needed for many governmental and business transactions. Many agencies are involved in their issuance and verification, while many types of driver's licenses exist across the states. This multiplicity of uses, agencies involved, and standards implies that seeking a stricter, shared driver's licenses system is a formidable endeavor. The REAL ID Act of 2005 has sought precisely such a profound regulatory transformation, bringing the United States closer to a de facto national identification system based on state driver's licenses. Overall, the Act establishes a revamped threshold of requirements for driver's license and identity card issuance and calls for the linking of each state's database. More specifically, the Act addresses the following: (i) minimum information that needs to be included in driver's licenses; (ii) a stricter set of source documents required for issuance, including proof of legal status in the United States, and tighter requirements to validate them with the vital records entity; (iii) confirmation of Social Security Number, or ineligibility; (iv) electronic scanning of source documents; (v) stricter renewal and termination requirements; (vi) stricter manufacturing and personnel requirements; and (vii) the provision of electronic access to all other states of all fields in driver's licenses. ${ }^{2}$

Many key aspects of the Act took several years to settle, with the final guidelines being announced by the Department of Homeland Security in January 2008 after consultation with Departments of Motor Vehicles, state associations, and other interested parties. This lengthy period of consultation did not preempt state-level opposition. At this time, 13 states have enacted legislation refusing to comply with the REAL ID Act, while 18 states have pending legislation (NCSL Database, 2008). ${ }^{3}$ The states have focused their concerns both on privacy issues and costs. For example, Idaho enacted a law in 2007 that directly prohibits the Transportation Department from implementing the provisions in the REAL ID Act, since the "potential breaches in privacy that could result directly from compliance with the REAL ID Act may violate the right to privacy of thousands of residents of Idaho." Furthermore, according to this law, "the U.S. Congress has pledged only $\$ 81.3$ million, or less than $1 \%$ of the total cost" (HB 606). New Hampshire's law finds the REAL ID Act "contrary and repugnant" to its constitution and to the U.S. Constitution (HB 685). However, all states have requested and been granted extensions to the initial May 11, 2008, deadline for compliance with the REAL ID Act. The final outcome from this Act then 
is still somewhat uncertain and, as more demanding implementation deadlines arrive, the debates will intensify. How the public responds when the implications of the reform become clearer and more imminent should be increasingly relevant to the evolution of this Act.

\section{Framing a Contentious Policy Issue}

The research on public opinion has repeatedly shown that frames or "patterns of selection, emphasis and exclusion that furnish a coherent interpretation and evaluation of events" can influence citizens' thoughts and support of issues (Norris, Kern, \& Just, 2003, based on Gitlin, 1980). As Sniderman and Theriault (2004) state, "how citizens think about a public issue, it now is widely if not universally agreed, depends on how it is framed" (p. 135; see also Gamson \& Modigliani, 1989). In particular, for issues for which citizens do not have a settled leaning, which, according to Zaller (1992), may be the case for many citizens and for many issues, a frame can provide a salient interpretation. Issue framings have been shown to influence many policy issues, such as those related to racial politics, welfare, civil liberties, government spending, and affirmative action, among others (Chong, 1996; Druckman, 2001; Iyengar \& Kinder, 1987; Jacoby, 2000; Nelson \& Kinder, 1996; Nelson, Clawson, \& Oxley, 1997; Nelson, Oxley, \& Clawson, 1997).

In this article, the examination of the public's attitudes toward personal identification is carried out mainly through a framing experiment on opinions on the REAL ID Act. The experimental design involves exposing randomly selected respondents to different frames that emphasize different interpretations of the REAL ID Act. There are five possible frames: two supportive frames (or frames that emphasize an interpretation conducive to support of the issue), one opposed frame (or frame that emphasizes an interpretation encouraging opposition to the issue), a contested or dual frame (a frame that presents both supportive and opposing interpretations), and no frame (a neutral or default frame).

Focusing first on one-sided frames, standard framing experiments have shown that these types of frames can induce positive or negative shifts in attitudes depending on the consideration being highlighted (e.g., Nelson \& Kinder, 1996; Nelson, Clawson, \& Oxley, 1997). For example, Nelson, Clawson, and Oxley (1997) showed that participants exposed to edited news coverage on a Ku Klux Klan rally emphasizing the event as a free speech issue (supportive frame) expressed higher levels of tolerance toward the Klan than those exposed to a comparable video emphasizing instead concerns with the disruption to public order (opposing frame).

In the present study's design, there are two supportive frames: one emphasizes "the threat of terrorism" as a motivation for the REAL ID Act, while the other emphasizes concerns with "the burdens of illegal immigration." Given that the inception of the law both legislative backers as well as the Department of Homeland Security stressed the concerns with national security as the rationale for the Act, it is possible that citizens may respond more strongly to such an interpretation than one stressing the burdens of immigration. In fact, in a Pew poll in September 2006, the year in which this study's survey was conducted, when asked about the most 
important problem facing the country at the time, 25 percent of respondents stated the war in Iraq (the most prevalent answer), 9 percent stated the economy, 14 percent stated terrorism, and only 6 percent stated immigration (Pew Research Center, 2006b). Furthermore, the Congressional 2006 elections focused in great part on the failures of the war in Iraq and the responsibility of the executive on this issue (Abramson, Aldrich, \& Rohde, 2007). However, immigration was not a completely forgotten item in the public discourse because Congress was debating at the time passing comprehensive immigration reform and the immigration issue was relevant for many House races (Abramson et al., 2007). Overall, this suggests the following expectation: both the "Terrorism Frame" and the "Immigration Frame" will elicit positive support toward the REAL ID Act, but the effect from the "Terrorism Frame" will be stronger.

The opposing frame points to concerns with violations of "civil liberties and privacy of average Americans." This has been one of the key criticisms of the REAL ID Act, apart from preoccupations with costs. But, as mentioned earlier public opinion polls have shown some willingness by Americans to give up civil liberties within the post 9/11 context in exchange for more security (Davis \& Silver, 2004; Pew Research Center, 2006a). In fact, according to Davis and Silver (2004) a higher trust in the government and a greater sense of threat of terrorism can significantly lower support for civil liberties. Based then on the framing literature the "Civil Liberties Frame" should decrease support for the REAL ID Act in comparison to the supportive frames, but based on public opinion data and research, this effect may be dampened if a sense of trust in the government is heightened and concerns with terrorism are present.

Sniderman and Theriault (2004) have pointed out that much of the framing (experimental) survey literature has often focused on one-sided frames, either supportive or opposing, without providing competing frames. Providing several contested frames may be more representative of the information process experienced in real life by citizens. Research emphasizing experimentally dual frames and even control frames where no frame is provided has only more recently been developed (e.g., Chong \& Druckman, 2005; Jacoby, 2006b). The survey design for this study has a contested frame that includes the considerations raised in the two supportive frames, that is, the burdens from terrorism and immigration, and the considerations from the opposing frame, that is, civil liberties and privacy. Sniderman and Theriault (2004) and Chong and Druckman (2006) argue that dual frames should be expected to moderate opinion by canceling or compounding framing effects. In the views of Sniderman and Theriault (2004) being exposed to opposing sides of an issue makes it more likely that respondents will decide more consistently according to their values. In contrast, Chong and Druckman (2006) argue that contested frames elicit opposing considerations, and the effect of the dual frames depends mainly on the strength, or the perceived persuasiveness, of each frame to elicit these dimensions.

Although often we might expect dual frames to produce intermediate positions between those generated by the supportive and opposing frames, the intermediate position need not be exactly in the middle. That is, dual frames do not necessarily cancel out contrasting effects. Further, dual frames may generate "backlash" effects 
if a weak frame is juxtaposed with a strong frame, and some respondents turn to the strong frame at higher rates than if only exposed to the strong frame (Chong \& Druckman, 2006, p. 8). In the present study the strengths of the frames were not tested. Moreover, previous research suggests individuals in the United States have a wide variability in their ranking of values such as liberty and social order (e.g., Jacoby, 2006a, 2006b). Therefore, there is no clear guidance on how influential the supportive frames are with respect to the opposing frame, and one can only venture that the dual frame will generate intermediate levels of support between those of the supportive and opposing frames.

The effects of frames are not expected to be the same across respondents but rather to be mediated by certain individual characteristics, such as knowledge and ideological leanings. With regard to knowledge, the theoretical accounts and the empirical findings are conflictive: some argue that more sophisticated respondents are less likely to be swayed, because many considerations on the issue are already more anchored in them (e.g., Zaller, 1992), while others posit that more sophisticated respondents may be more likely to comprehend conflictive considerations, making them more likely to respond to the frames (e.g., Miller \& Krosnick, 2000; Nelson, Oxley, \& Clawson, 1997). But, in terms of individual moderators what is possibly of more interest to this study are political attitudes. The framing literature suggests that individuals with strong priors on an issue will be less susceptible to be influenced by frames contrary to their beliefs and more susceptible to be influenced by congruent frames (e.g., Brewer, 2003; Chong \& Druckman, 2007). According to this, those strongly concerned with terrorism, for example, will be more susceptible to a frame stressing terrorism concerns and less susceptible to one stressing civil liberties when deciding whether to support the REAL ID Act.

What is also relevant to this study and is yet unexamined is the role of political attachments on the issue of personal identification, independent of framing effects. That is, are Republicans and conservatives in general more supportive of further standardization in personal IDs than either Democrats or liberals? The working hypothesis is that party ID and ideology will modestly structure support levels for the REAL ID Act. For one, conservatives may not be unified in their support for more secure identification standards because a considerable number of citizens are libertarian conservatives or ideologically ambivalent, who might view such reforms as unwanted government entrenchments. ${ }^{4}$ Furthermore, the emergent debate on the REAL ID Act at the congressional and state levels has not taken distinct partisan lines, with no single party declaring the issue or its opposition strictly under their domain. This implies that while we may expect Republican respondents and some conservative respondents to be in general more concerned with national security and immigration, their party and ideological attachments may not guarantee their support of identification reforms.

All in all, based on previous research, public opinion polls, and the general political climate the following conjectures are made: (i) a majority of the public will favor personal identification reforms such as those in the REAL ID Act, (ii) the "Terrorism Frame" will induce higher support for the Act than the "Immigration Frame," while a balanced frame will induce intermediate levels of support between 
the supportive and opposing frames, and (iii) ideological leanings and party affiliation will modestly shape support for the REAL ID Act.

\section{Data and Methodology}

The main data for this project comes from a battery of questions designed by the author and added to the State of the State Survey (SOSS), a quarterly survey of Michigan residents conducted by the Institute for Public Policy and Social Research at Michigan State University. The survey was a regionally stratified random-digitbased telephone survey conducted between August 10 and October 21, 2006 (for more details see Hembroff, 2007). The sample had 993 completed interviews (completion rate of 37.7 percent) and the average interview lasted 23.7 minutes. The data is weighted in relation to age, gender, race, number of phone lines and adults in the household, and the number of respondents across counties to render it representative of the 18-and-over Michigan population. ${ }^{5}$

The questions related to personal identification sought to elicit opinions on the level of support for a national ID and then the level of support for the different components of the REAL ID Act as well as the Act overall. More specifically, the first question inquired about the level of approval, or disapproval, if the U.S. government were to introduce a national identity card, without mentioning the REAL ID Act as such. A follow-up, open-ended question sought reasons of concern with a national ID among those who disapproved of introducing such cards. The next set of questions dealt with the key features implied by the REAL ID Act. In particular, respondents were asked about their opinion (oppose/favor) on the following reforms implied by the Act: (i) more detailed documentation for issuance and renewal of IDs, (ii) more thorough validation and copying processes, which can entail higher fees and longer waits, (iii) the requirement that noncitizens show proof of legal status, (iv) bar codes or magnetic strips in IDs to electronically store basic personal identification information, and $(\mathrm{v})$ the requirement that states share with each other the collected ID information. Respondents were also queried with regards to their support for the use of REAL IDs in the context of voting for federal elections and for banking and credit card transactions. The final question asked for respondents' overall level of approval for the REAL ID Act. The complete set of questions is provided in Appendix A.

As mentioned earlier, the questionnaire included an experimental design. Before support for the specific items of the REAL ID was sought, respondents were provided with a brief description of the Act and then, randomly, they were also provided with a varying additional account or frame. That is, all respondents were read the main description of the Act:

In May 2005, Congress passed the Real ID Act which created federal standards for driver's licenses and personal ID cards. The Department of Homeland Security will set the standards which must be implemented by all states by 2008 . 
Next, respondents were randomly assigned to one of four treatments and a control, or five alternatives. Those assigned a treatment were read an additional account emphasizing the following: the threats of terrorism ("terrorism frame"), the burdens of immigration ("immigration frame"), the erosion of civil liberties and privacy ("civil liberties frame"), and the trade-offs between reducing the threats of terrorism and illegals, and the loss of civil liberties ("balanced frame"). Those assigned to the control or neutral case ("no frame") were not read anything else in addition to the preliminary description of the Act.

The frames emphasizing the threats of terrorism and illegal immigration can provide positive grounds for the reform of identification systems:

Some people say that the Real ID Act is necessary in order to reduce the threat of terrorism in this country by limiting the ability of terrorists to move freely in our society. (Terrorism frame.)

Some people say the Real ID Act is necessary in order to reduce the burdens from illegal immigration by limiting the ability of illegal aliens to move freely in our society. (Immigration frame.)

The frame on civil liberties and privacy, on the other hand, can point to the qualifications and potential drawbacks from such efforts:

Some people say the Real ID Act could violate the civil liberties and privacy of average Americans by increasing the government's ability to track every person's actions and personal information. (Civil liberties frame.)

while the "balanced frame" presents both positive and negative accounts:

Some people say that the Real ID Act is necessary in order to reduce the threat of terrorism and illegal immigration in this country, while others say the Act could violate the civil liberties and privacy of average Americans.

(Balanced frame.)

The "no frame" or default case is, in principle, the baseline case since no new information is provided in addition to the basic introduction. In terms of presenting support levels for the REAL ID Act that may be reflective of the general population, I will report those values for the respondents assigned to the "No Frame" case $(\mathrm{N}=175)$. Note, however, that the frames are introduced after the first question on approval of a national ID card, therefore responses to the national ID question are not influenced by the experiment.

\section{Results}

\section{Aggregate Trends}

The majority of Michigan respondents support the introduction of a national ID by the U.S. government as seen in Figure 1. More specifically, 61 percent of respondents from the whole sample $(\mathrm{N}=945)$ supported their introduction, with around 26 


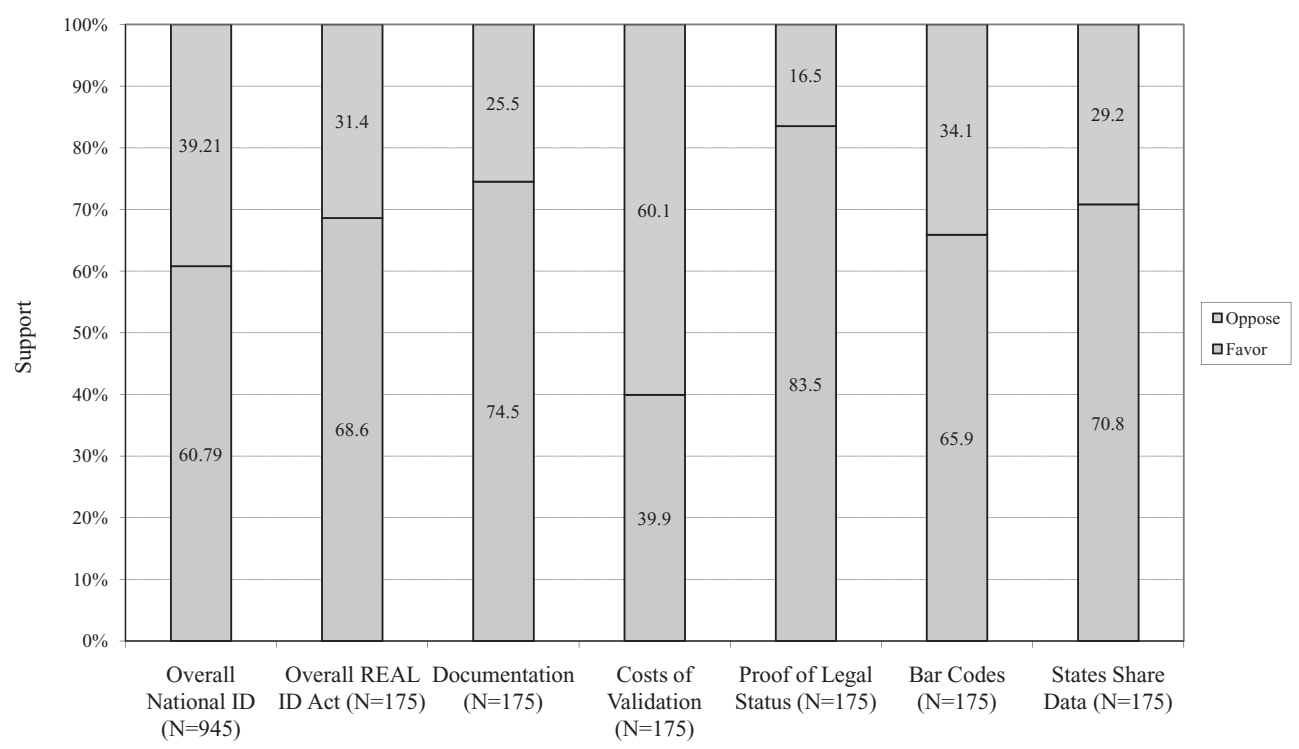

Figure 1. Michigan Respondents' Support (\%) for National IDs and the REAL ID Act, 2006.

percent strongly approving and the remaining 35 percent somewhat approving. Respondents who disapproved of national IDs were prompted in a follow-up question to state their main concern. The most commonly provided apprehension was related to "too much government intervention/do not trust government (25\%);" the second most frequent worry was related to being "unnecessary/already have IDs in place $(22 \%) ; "$ and the third most common mention was related to "violates freedoms/endangers rights/right to privacy (15\%)." The sentiments of distrust of the government as well as the believed adequacy of existing identification systems seem to motivate most of those who disapprove of national IDs. By comparison, concerns with privacy and rights (15 percent), identity theft (10 percent), and costs (2 percent) are more infrequent.

Turning to the REAL ID Act, we observe higher levels of support for this reform than for national IDs: close to 69 percent of respondents from the neutral frame sample $(\mathrm{N}=175)$ supported the REAL ID Act compared to 61 percent supporting a national ID. This is not too surprising in that the REAL ID Act is a less stringent policy: we would expect any citizen who supports national IDs to be more likely to also support REAL IDs. In fact, among those who approved of national IDs and were then exposed to the default frame, 93 percent approved of the REAL ID Act.

Focusing now on the different components of the REAL ID Act, Figure 1 shows as well the level of support for each critical feature among the default frame respondents. Four of the five key dimensions of the Act obtain majority support of over 60 percent, with the requirement of proof of legal status eliciting the largest support, at 83 percent. Quite importantly, one potential implication of the act-higher fees and higher waiting time-is distinctly not favored by respondents, with just 40percent support. That is, respondents approve of most requirements, including more 
Table 1. Effect of Frames on Michigan Respondents' Support (\%) for the REAL ID Act, 2006

\begin{tabular}{|c|c|c|c|c|c|}
\hline & $\begin{array}{c}\text { "No } \\
\text { Frame" } \\
(\mathrm{N}=175)\end{array}$ & $\begin{array}{c}\text { “Terrorism" } \\
(+) \\
\text { Frame } \\
(\mathrm{N}=189)\end{array}$ & $\begin{array}{c}\text { "Immigration" } \\
(+) \\
\text { Frame } \\
(\mathrm{N}=190)\end{array}$ & $\begin{array}{c}\text { “Civil Liberties" } \\
(-) \\
\text { Frame } \\
(\mathrm{N}=168)\end{array}$ & $\begin{array}{c}\text { "Balanced" } \\
( \pm) \\
\text { Frame } \\
(\mathrm{N}=215)\end{array}$ \\
\hline \multicolumn{6}{|l|}{ Main sample } \\
\hline Overall approval & 68.6 & 73.8 & $77.7^{* *}$ & 70.6 & 62.3 \\
\hline Republican & 78.0 & 76.0 & 89.7 & 86.6 & 78.0 \\
\hline Democrat & 73.7 & 73.4 & 69.1 & 67.2 & $53.2^{* *}$ \\
\hline Independent & 47.6 & $68.4^{*}$ & $86.7^{* *}$ & $68.6^{* *}$ & $71.6^{* *}$ \\
\hline Conservative & 74.1 & 82.8 & 80.5 & 73.2 & 72.4 \\
\hline Liberal & 52.7 & 56.7 & $79.5^{* *}$ & $75.5^{*}$ & 47.3 \\
\hline Trust federal government & 79.1 & 79.9 & 81.5 & 78.1 & $62.6^{* *}$ \\
\hline Do not trust government & 54.9 & 65.1 & $68.9^{*}$ & 63.4 & 61.6 \\
\hline Concerned with terrorism & 74.7 & 76.4 & 80.5 & 75.4 & 66.4 \\
\hline Not concerned & 56.9 & 67.9 & 65.9 & $48.7^{*}$ & 53.7 \\
\hline Illegal immigration important & 72.1 & 76.5 & $82.0^{* *}$ & 73.8 & $63.4^{*}$ \\
\hline Not important & 35.7 & 40.5 & 20.2 & 40.9 & 47.6 \\
\hline College degree & 63.2 & 76.4 & 80.0 & 76.4 & 77.4 \\
\hline No college degree & 70.1 & 73.0 & 76.9 & 69.5 & $56.5^{* *}$ \\
\hline
\end{tabular}

Note: Overall approval is the percentage of respondents who "Strongly Approve" or "Somewhat Approve" of the REAL ID Act. Differences of proprotions tests are shown only with respect to the "No Frame" proportion.

${ }^{* *}$ Indicates $p$-values $<0.05,{ }^{*}$ indicates $p$-values $<0.10$ (two-tailed tests).

demanding documentation and even data sharing across the states, but seem less willing to bear some of the potential costs these reforms may entail. ${ }^{6}$

Overall then, within the Michigan sample the prospects of a national ID card and the new cards emanating from the REAL ID Act are clearly viewed positively. Respondents strongly support many of the core requirements of the Act; however, the provision of heightened validation and its potential for higher fees and delays does not elicit majority support.

\section{Framing Experiment}

A critical design of this project is the influence of different frames on the approval of the REAL ID Act and its various features. Table 1 presents overall levels of support for the Act across the five frames, for the whole sample as well as for specific subgroups. Table 2 presents the levels of support for each of the critical components of the Act across the five frames. For clarity both tables indicate significance levels only from differences of proportions tests with respect to the default case, although, clearly, many of the conjectures of interest involve comparisons among the other frames, and the results of these will be discussed in the text. Taken together, there is overall evidence of framing effects for the approval rates (first row) as revealed by a Cramer's $V$ test of association for nominal variables (0.07), although the Chi-squared test for independence is more marginal $(p r=0.11)$. 
Table 2. Effect of Frames on Michigan Respondents' Support (\%) for the Components of the REAL ID Act, 2006

\begin{tabular}{lccccc}
\hline & $\begin{array}{c}\text { "No } \\
\text { Frame" }\end{array}$ & $\begin{array}{c}\text { "Terrorism" } \\
(+) \\
\text { Frame }\end{array}$ & $\begin{array}{c}\text { "Immigration" } \\
(+) \\
\text { Frame } \\
(\mathrm{N}=175)\end{array}$ & $\begin{array}{c}\text { "Civil Liberties" } \\
(-) \\
\text { Frame } \\
(\mathrm{N}=189)\end{array}$ & $\begin{array}{c}\text { "Balanced" } \\
( \pm)\end{array}$ \\
\hline Frame \\
Components & & & & & $790)$ \\
Documentation & 74.5 & 76.9 & $85.1^{* *}$ & 74.1 & 74.7 \\
Costs of validation & 39.9 & 42 & $50.9^{* *}$ & 38 & 39.9 \\
Proof legal status & 83.5 & $91.5^{* *}$ & $92.3^{* *}$ & 89.5 & $93.2^{* *}$ \\
Bar codes & 65.9 & 71.4 & 70.8 & 70.9 & 60.8 \\
States share & 70.8 & 76.2 & $84.2^{* *}$ & 64.4 & $80^{* *}$ \\
\hline
\end{tabular}

Note: Percentages represent those who "Support" a component of the Act. Differences of proportions tests are shown only with respect to the "No Frame" proportion.

**Indicates $p$-values $<0.05$ and *indicates $p$-vlaues $<0.10$ (two-tailed tests).

Beginning with Table 1 and overall levels of support for the Act, we observe that both the "immigration frame," at 77 percent, and the "terrorism frame," at 74 percent, induce positive shifts in support with respect to the default frame, at 68 percent, although only the former shift is statistically significant $(p-v=0.05)$. Highlighting immigration induces more support than stressing terrorism, but the differences between them are not statistically significant. Contrary to the conjecture then, when it comes to identification issues respondents seem to be reacting as keenly from the burdens of immigration as from the burdens of terrorism.

The percentage of respondents supporting the Act in the "civil liberties" frame, 70 percent, cannot be distinguished from the default frame's percentage, though it is statistically significantly lower than the "immigration frame's" $(p-v=0.10)$. There are several possible explanations for the opposing frame not inducing a strictly lower level of support than the neutral frame. First, the frame on civil liberties may be a weak frame or a not sufficiently persuasive one, in the terminology of Chong and Druckman (2006). This seems an unlikely explanation, however, since concerns with civil liberties and core values associated with them are quite prevalent in the American political discourse. Another explanation is that stressing concerns with civil liberties but also the ability of the government to track personal actions and information may have indirectly increased the saliency of the issue of security for certain respondents (e.g., Independents), and thereby operated more as a supportive frame for them. Finally, we should note that as Sniderman and Theriault (2004, p. 150) point out the default frame, without a consideration being stimulated, does not imply "an absence of argumentation altogether." For some respondents the issue of personal IDs may already in and of itself be anchored around considerations of civil liberties.

The support level in the "balanced frame," 62 percent, is lower though statistically indistinguishable from the level of support in the default frame. That is, the dual frame is not presenting an intermediate level of support between those in the supportive and opposing frames, as conjectured, but rather it compounds the effect 
strictly downward. This result is in part a consequence of the previous finding that the frame on civil liberties does not operate as an opposing frame for all respondents because it actually raises the support for some. It is also driven by those who when exposed to contested arguments react in a strictly opposing fashion rather than by compounding considerations (e.g., those without a college degree).

Background characteristics and predispositions can mediate some of the observed framing effects, though multivariate analyses (conducted in the next section) are needed to properly understand them. At the bivariate level these mediating influences are in general either minor or selective. For example, whether a respondent has a college degree or trusts the government only differentially influences respondents exposed to the dual frame. In terms of prior issue positions, those who consider illegal immigration important were more susceptible to the frame on immigration, compared to the default frame, but those concerned with terrorism were not more susceptible to the frame stressing terrorism. ${ }^{7}$ In terms of ideology and party ID, all frames systematically influenced Independents in a supportive manner compared to the default frame, suggesting the experimental treatments made the issue of identification more salient to them, regardless of the content in them. Republicans and Conservatives, on the other hand, were not more susceptible to any of the frames; while Liberals, seemingly in reaction, were in particular susceptible to the frames on immigration and civil liberties in a supportive way.

What is also relevant to examine is whether ideology and party ID structure levels of support for the reform in general, independent of the framing experiment. Focusing then on the default frame's respondents, we see that 78 percent of Republicans approved of the Act, while 74 percent of Democrats did so. These rates are statistically undistinguishable suggesting party identification is not a critical predictor. On the other hand, ideology may prove more influential: Conservatives at 74 percent are significantly more likely than Liberals at 53 percent to support the reform $(p-v=0.03)$.

Turning to the components of the REAL ID Act, Table 2 reveals that the "immigration frame" once more induces the most notable effects. This frame increases the support in a statistically significant manner for four of the five critical components of the Act. Quite importantly, under this frame, 51 percent of respondents support higher costs and delays to improve validation, compared to 39 percent among the default frame respondents. None of the other frames displays many framing effects. The component most susceptible to framing effects is the proof of legal status: all frames increase the support for this component in comparison to the default frame.

In sum, only the "immigration frame" generated a shift in support with respect to the default frame in terms of overall approval and with regards to many of the critical components of the Act. Raising concerns with civil liberties did not create more opposition to the Act with respect to the default frame and presenting balanced explanations did not generate intermediate levels of support. However, support in the dual frame is significantly lower than in the frame on immigration which suggests that if more balanced discourses prevail in comparison to one in which immigration concerns dominate, support will be dampened. 


\section{Multivariate Analyses}

To better understand the moderators of framing effects as well as the correlates of support several probit specifications (Table 3) were estimated predicting a respondent's approval of the REAL ID Act. In model 1 only respondents from the default case are included; in model 2 all respondents are included and the frames are controlled for, while in model 3 the frames are also interacted with selected key independent factors. All the specifications include relevant factors (e.g., level of concern with terrorism, importance of immigration, and trust in government) as well as standard demographic controls. In general, demographic factors have a lesser role in explaining support for the Act, with the exception of being U.S. born. What can be explained of support is driven mainly by prior dispositions and framing influences.

A quick glance over models 2 and 3 reveals that as in the aggregate analysis the frame emphasizing immigration burdens significantly increases support with respect to the default frame. This increase is of 0.10 points in model $2(p-v=0.06)$. In model 3 the effect of the frame on immigration manifests itself through the interaction term with concern with immigration. More specifically, exposure to the frame on immigration among those concerned with immigration increases support by 0.14 points (95 percent $C I=0.04,0.24$ ); among those not concerned with immigration the effect of this frame is undistinguishable from no effect.

In terms of the correlates of support for the REAL ID Act, considering illegal immigration is an important issue, has a consistently strong effect across all models, and is more relevant than ideology. For example, concern with immigration increases support for the reform by 0.45 points in model 1 and by 0.35 points in model 2. Concern with terrorism and trust in the government are also substantively and statistically relevant when examining the full sample; however, their effects are more modest in comparison to immigration concerns. A respondent is 0.13 points more likely to support the Act in model 2 if he is concerned about a terrorist attack and 0.17 points more likely to do so if he trusts the government. Ideology also structures support for the Act but in an even weaker manner: in model 2 Conservatives are 0.08 points more likely to support the reform than moderates and 0.12 points more likely than liberals. ${ }^{8}$ However, the effect of ideology and partisanship may be more indirect, by shaping prior dispositions such as trust in government or concern with immigration.

With regards to the moderators of framing effects, little support was found for the need of a fully interacted model, and in general these effects are more minor. No systematic interactive effects were found with respect to ideology, education, or partisan ID. The interaction terms in model 3 are the ones we may theoretically more strongly expect to be relevant (e.g., if concerned with terrorism and exposed to the terrorism frame we may expect a differential impact). As mentioned earlier we do find a mediating effect between being concerned with illegal immigration and being exposed to the frame on immigration.

All in all, the multivariate analyses are in line with the findings in the aggregate breakdowns: they further highlight the effects of the frame on immigration and in general reveal the preeminence of immigration concerns. In addition, these analyses 


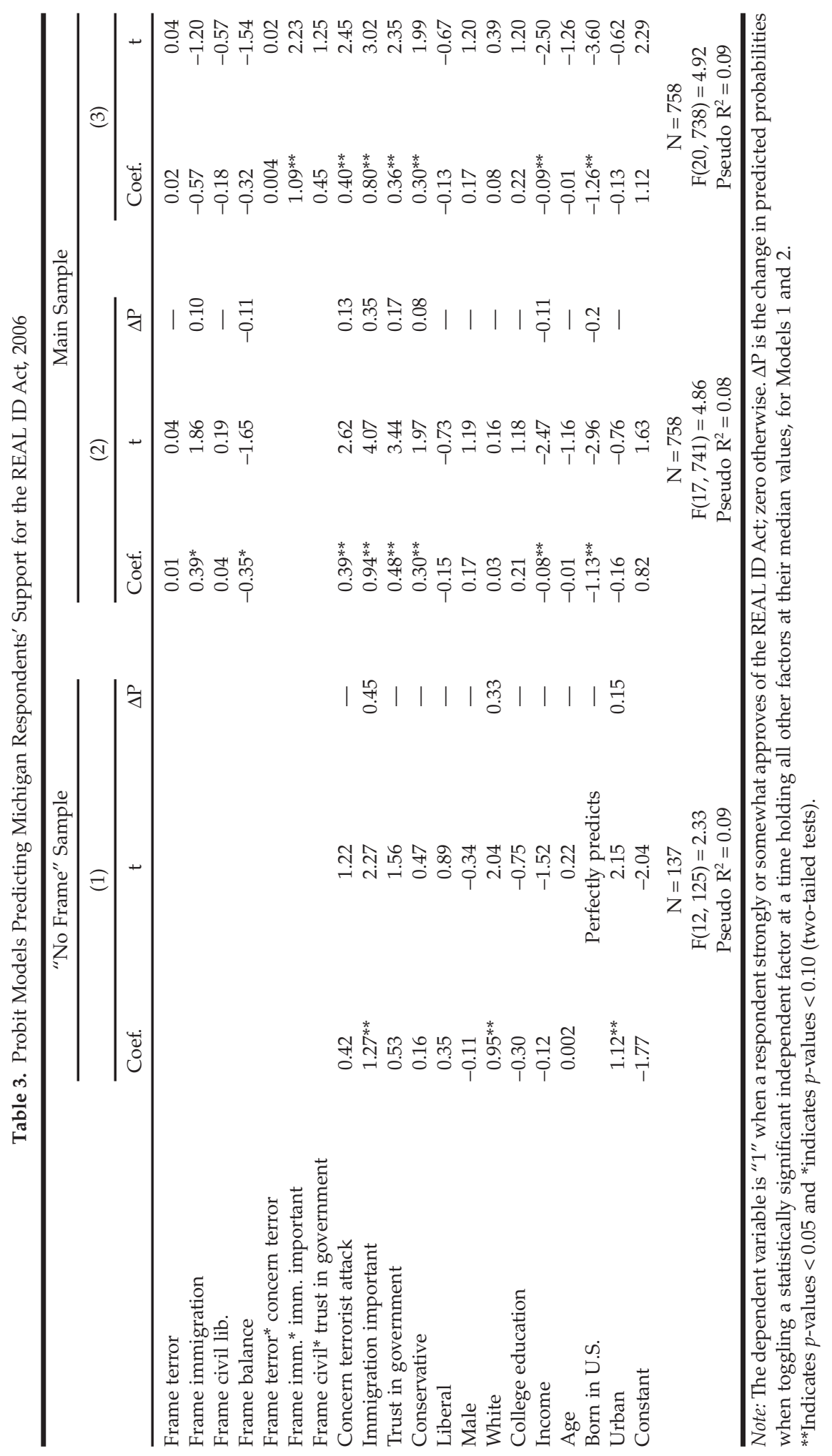


clarify the relative modest (direct) influences of ideological and partisan leanings. Other predispositions, such as concern with terrorism and trust in the government are also shown to be relevant to understanding support for the REAL ID Act reforms, though to a lesser degree than immigration concerns.

\section{National Trends}

The main results for this study have been derived from Michigan respondents. A natural inquiry is how generalizable some of these findings are to the nation as a whole. To the author's knowledge there have been no national surveys that have addressed the REAL ID Act, therefore comparisons can only be made in terms of support for a national ID. The tendencies revealed in existing national surveys on dispositions toward a national ID are in general accordance with those found in the Michigan survey. Table 4 presents the percentages supporting a national ID from various national surveys as well as for the Michigan survey. A majority of Americans favors requiring that all citizens carry a national identity card at all times, reaching 60 percent support in 2006, a very comparable level to Michigan's support of 61 percent at that time.

In terms of background predispositions and support for a national ID examined at the bivariate level, the Michigan survey also displays quite analogous results to the national surveys. For example, in both settings (national and Michigan) ideology seems to provide a link to support of national IDs, although the influence of trust in government seems to be stronger. However, to properly account for background characteristics multivariate analyses are needed and these were carried out for the national Civil Liberties surveys and the Michigan survey, as seen in Appendix B. In general, we find that when explaining support for a national ID in the national samples trust in government is statistically influential but neither ideology nor concern with terrorism is a driving force. Comparable results obtain for the Michigan sample, with the distinction that concerns with terrorism do matter in the Michigan context but take a second place to concerns with immigration (as it did for the REAL ID Act). ${ }^{9}$ These preliminary comparisons suggest that Michigan is not a stark outlier in terms of public opinion in the realm of identification reform: both the Michigan and national samples display majoritarian support for a national ID ( $\sim 60$ percent), a substantive role for trust in government, and minor (direct) ideological linkages. Concern with terror is not the leading factor in either setting. While clearly more research awaits that tests at the national level and for the REAL ID Act the experimental designs from this study, it would seem some initial lessons can be taken from the Michigan results.

\section{Discussion}

From a policy perspective, this paper reveals that within the Michigan public there is a favorable disposition toward national IDs or reforms moving in that direction, such as the REAL ID Act. These sentiments are also reflected at the national level. However, based on the Michigan context there is little disposition to bear the 


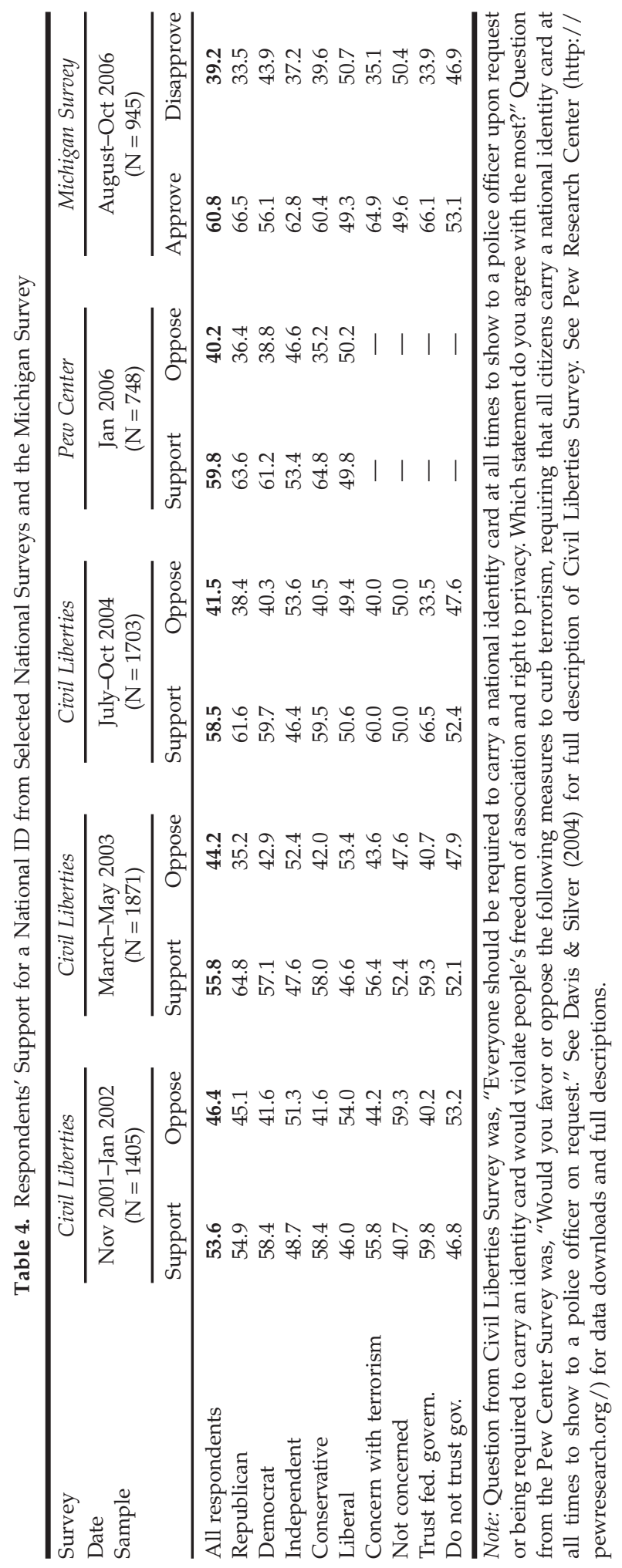


costs of such reforms. Moreover, framing the issue around the burdens of illegal immigration can generate as much support, if not more, as framing the issue around terrorism while providing a fuller array of implications around IDs can erode support. Personal identification is being weakly assessed through ideological and partisan attachments while trust in the government is relevant to this assessment in both the national and Michigan settings. All in all, this suggests there is a comfortable margin for reforms around identification if public protection interpretations dominate.

From the perspective of the framing literature, this study's experimental design shows that framing effects can be found in the policy arena of personal identification. However, the results were not all as expected. For example, the opposing frame stressing civil liberty concerns actually increased the support for some respondents, possibly by positively drawing attention to the government's abilities to track personal information. There is then clearly more to be understood about citizens' willingness to balance privacy versus social order concerns. But also many Americans are possibly unfamiliar about reforms in personal identification in general. That is, this is an emergent policy issue and public opinion can still evolve, in contrast to other policy areas such as welfare reform, for which citizens may already have more solid predispositions.

This in turn suggests that the media, political elites, and current events have the potential to further prod the general public's attitudes toward ID reforms. At this time immigration seems to be the more surefire trigger than the threats from terrorism, at least in the Michigan context. Even though the REAL ID Act was motivated by recommendations from the 9/11 Commission and this Act was originally framed by the government in terms of improving national security, citizens at present seem to respond more strongly to an appeal framed in terms of lessening the burdens of illegal immigration. The Bush administration's near complete omission of the matter of illegal immigration when first referring to the REAL ID Act in 2006 may have been strategic: it could have gone against its attempted efforts to enlist broader support from the Hispanic population, including via work/legalization programs prior to the 2006 elections. However, quite meaningfully, since 2006, the Department of Homeland Security has started to emphasize more immigration in its rationales for the Act. For example, Secretary Chertoff when announcing the new guidelines for the REAL ID Act in January, 2008, stated that the second reason for secure driver's licenses was to "prevent illegal immigrants from pretending to be American citizens"; the first reason though was still to prevent "dangerous people from getting on airplanes or getting into federal buildings" (Secretary Chertoff, 2007).

Both the Michigan and the national samples reveal that trust in the government is also relevant to understand support for reforms in personal identification. Within the Michigan sample and among those who disapproved of national IDs the most commonly cited explanation for this opposition was "too much government intervention/do not trust government" (p. 17). Ideological and party affiliations on the other hand were somewhat less critical influential factors on the support of identification reforms. The issue of personal identification is not being presented or interpreted in strict ideological or partisan terms, much in the way that certain other 
security-related issues (e.g., the Patriot Act renewal of 2006) have not been endorsed in strict partisan terms. A government keen on implementing identification reforms may be better off emphasizing tamper-proof precautions and the trustworthiness of the general reform than pure ideological grounds.

The "tinkering" toward national identification standards is actually not limited to the arena of personal identification since the states are also engaging in reforms with regards to student identification systems (partly as a result of the No Child Left Behind Act of 2001) and voter identification and registration lists (partly as a result of the HAVA Act of 2002). Many of these reforms have remained opaque to the general public, though some of the same issues, such as privacy and civil rights concerns, costs, and state implementation difficulties, have arisen. This paper has suggested that within the American context public opinion is at this early stage sympathetic to reforms to personal identification, though not unmovable. State representatives will now face their arduous task of assessing from their vantage point, taking into consideration public opinion and the federal mandate, whether these reforms are indeed welfare improving.

Valentina Bali is an Associate Professor at Department of Political Science, Michigan State University, East Lansing, MI 48824, USA.

\section{Notes}

1. The original deadline for the implementation of the REAL ID Act was May 11, 2008. However, the Department of Homeland Security revised its guidelines and time schedules to now take place starting December 31, 2009.

2. The full text of the Act can be viewed at the Department of Homeland Security: http:/ /www.dhs.gov.

3. The states having enacted legislation refusing to comply with the REAL ID Act are: Colorado, Hawaii, Idaho, Illinois, Maine, Michigan, Montana, Nebraska, New Hampshire, Oklahoma, South Carolina, Tennessee, and Washington.

4. According to a 2006 Pew poll (2006c) that classified respondents along two dimensions, economic conservatism and social liberalism, in the United States there are 18 percent liberals, 15 percent conservatives, 16 percent populists (economically liberal but socially conservative), 9 percent libertarians (economically conservative but socially liberal), and 42 percent ambivalent.

5. The sample weight used from the IPPSR survey was AGEWT. The weights are top censored at the value of 7 to avoid unreasonably high weight values (this affects only three observations). The weight STATEWT, which also accounts for the proportion of cases across regions (AGEWT does this across counties), was not used since there are 13 observations with extremely high weight values. Although the interpretation of the results remains largely the same irrespective of the weight scheme used, the sample weight construction from IPPSR surveys requires attention.

6. The survey also included two questions regarding the use of the REAL IDs in the context of voting in federal elections (76 percent support) and for banking and credit card transactions (only 55 percent support).

7. The question on concern on terrorism asked: "All in all, how concerned are you that the United States might suffer another terrorist attack in the next 3 months?" The question on immigration asked: "How important is the issue of illegal immigration?" The question on trust in the government asked: "How much of the time do you trust the government in Washington to do what is right?"

8. To reduce collinearity concerns between ideology and partisanship separate models (available from the author) were estimated for party ID. Partisanship factors were found to have comparable moderate 
effects: in model 2 Republicans are 0.10 points more likely to support the Act than Independents and 0.12 points more likely than Democrats.

9. Unfortunately, though, the comparisons between the Michigan and national specifications are limited in that the national surveys do not include a control for the importance of immigration to the respondent.

\section{References}

Abramson, Paul. R., John H. Aldrich, and David Rohde. 2007. Change and Continuity in the 2004 and 2006 Elections. Washington, DC: CQ Press.

Brewer, Paul R. 2003. "Values, Political Knowledge, and Public Opinion About Gay Rights: A FramingBased Account." Public Opinion Quarterly 67: 173-201.

Chong, Dennis. 1996. "Creating Common Frames of Reference on Political Issues." In Political Persuasion and Attitude Change, ed. Diana C. Mutz, Richard A. Brody, and Paul M. Sniderman. Ann Arbor, MI: The University of Michigan Press, 195-224.

—, and James N. Druckman. 2005. "Competitive Framing." Northwestern University. Manuscript.

- 2006. "Democratic Competition and Public Opinion." Northwestern University. Manuscript.

—. 2007. "Framing Theory." Annual Review of Political Science 10: 103-26.

Davis, W. Darren, and Brian D. Silver. 2004. “Civil Liberties vs. Security: Public Opinion in the Context of the Terrorist Attacks on America." American Journal of Political Science 48 (1): 28-46.

Druckman, James N. 2001. “On the Limits of Framing Effects: Who Can Frame?" The Journal of Politics 63 (4): 1041-66.

Gamson, William A., and Andre Modigliani. 1989. "Media Discourse and Public Opinion: A Constructionist Approach." American Journal of Sociology 95: 1-37.

Gitlin, Todd. 1980. The Whole World is Watching. Berkeley: University of California Press.

Hembroff, Larry. 2007. “Methodological Report [MSU-SOSS 43].” MSU: Manuscript.

Home Office. 2004. "Identity Cards: A Summary on the Findings from the Consultation on Legislation on Identity Cards." http:/ / www.archive2.official-documents.co.uk/document/cm63/6358/6358.htm. Accessed June 20, 2008.

_ 2006. "Strategic Action Plan for the National Identity Scheme." http://www.homeoffice.gov.uk/ documents/strategic-action-plan.pdf?version=1. Accessed May 14, 2007.

ICM Research. 2006. ID Card Survey. http://www.icmresearch.co.uk/pdfs/2006_july_no2id_id_card_ survey.pdf. Accessed June 20, 2008.

Iyengar, Shanto, and Donald R. Kinder. 1987. News that Matter: Television and American Opinion. Chicago: Chicago University Press.

Jacoby, William G. 2000. "Issue Framing and Public Opinion on Government Spending." American Journal of Political Science 44 (4): 750-67.

—. 2006a. "Testing for Hierarchical Structure and Priming Effects Among Individual Value Choices" Michigan State University: Manuscript. http://polisci.msu.edu/jacoby/research/values/vallist. html. Accessed August 29, 2008.

- 2006b. "Value Choices and American Public Opinion" Michigan State University. Manuscript: http://polisci.msu.edu/jacoby/research/values/vallist.html. Accessed August 29, 2008.

Miller, Joanne M., and Jon A. Krosnick. 2000. "News Media Impact on the Ingredients of Presidential Evaluations." American Journal of Political Science Review 91: 567-83.

National Conference of State Legislatures (NCSL). 2008. "Real ID State Legislation Database." http:// www.ncsl.org/standcomm/sctran/RealIDdb.cfm. Accessed June 18, 2008.

Nelson, Thomas E., Rosalee Clawson, and Zoe M. Oxley. 1997. "Media Framing of a Civil Liberties Conflict and its Effect on Tolerance." American Political Science Review 91 (3): 567-83. 
— Journal of Politics 58 (4): 1055-78.

, Zoe M. Oxley, and Rosalee Clawson. 1997. "Towards a Psychology of Framing Effects." Political Behavior 19 (3): 221-45.

Norris, Pipa, Montague Kern, and Marion Just (eds.) 2003. Framing Terrorism: The News Media, the Government, and the Public. New York: Routledge.

Pew Research Center. 2006a. “Americans Taking Abramoff, Alito, and Domestic Spying in Stride January 11, 2006." http:/ / people-press.org/reports/pdf/267.pdf. Accessed June 20, 2008.

—. 2006b. "Democrats Hold Solid Lead Report September 14, 2006." http://people-press.org/ reports/pdf/289.pdf. Accessed August 25, 2008.

- 2006c. "In Search of Ideologues in America, April 11, 2006." http://pewresearch.org/pubs/17/ in-search-of-ideologues-in-america. Accessed June 2, 2008.

Polling Report. 2001. “Newsweek Poll 2001 conducted by Princeton Survey Research Associates." http: / / www.pollingreport.com/terror8.htm. Accessed May 14, 2007.

Secretary Chertoff. 2007. "Remarks by Secretary Chertoff on the REAL ID." http://www.dhs.gov/ xnews/releases/pr_1172834392961.shtm. Accessed May 14, 2007.

Sniderman, Paul M., and Sean M. Theriault. 2004. "The Structure of Political Argument and the Logic of Issue Framing." In Studies in Public Opinion: Attitudes, Non-Attitudes, Measurement Error, and Change, Princeton, NJ: Princeton University Press, 94-133.

SOSS. 2006. What Is the State of the State Survey? http://ippsr.msu.edu/soss/. Accessed June 6, 2008.

The 9-11 Commission Report. 2004. "Final Report of the National Commission on Terrorist Attacks." http:/ / www.gpoaccess.gov/911/index.html. Accessed May 14, 2007.

Wadham, John, Caoilfhionn Gallagher, and Nicole Chrolavicius. 2006. Blackstone's Guide to the Identity Cards Act 2006. Oxford, UK: Oxford University Press.

Zaller, John R. 1992. The Nature and Origins of Mass Opinion. New York: Cambridge Press.

\section{Appendix A}

Below are the questions designed by the author and included in State of the State Survey (SOSS, 2006) 43.

ID1. The next set of questions focus on national identity cards, which are official documents issued by a government with the intent to prove a person's identity. These cards typically include a name, an identification number, birth date, present address, and gender. Would you strongly approve, somewhat approve, somewhat disapprove, or strongly disapprove of the U.S. government introducing a national identity card?

ID2. (For those who disapprove in ID1). What is your main concern?

ID3. In May 2005, Congress passed the Real ID Act which created federal standards for driver's licenses and personal ID cards. The Department of Homeland Security will set the standards which must be implemented by all states by 2008 .

ID3a. No treatment.

ID3b. Some people say that the Real ID Act is necessary in order to reduce the threat of terrorism in this country by limiting the ability of terrorists to move freely in our society. 
ID3c. Some people say the Real ID Act is necessary in order to reduce the burdens from illegal immigration by limiting the ability of illegal aliens to move freely in our society.

ID3d. Some people say the Real ID Act could violate the civil liberties and privacy of average Americans by increasing the government's ability to track every person's actions and personal information.

ID3e. Some people say that the Real ID Act is necessary in order to reduce the threat of terrorism and illegal immigration in this country, while others say the Act could violate the civil liberties and privacy of average Americans.

ID4. Next I am going to read you a list of requirements of the Real ID Act and have you tell me if you favor or oppose each.

ID4a. The Real ID Act requires people to provide documents with their birth date, name, principal address, and social security number when applying for or renewing driver licenses or personal ID cards. (Do you support or oppose this provision?)

ID4b. The Real ID Act requires the Michigan Secretary of State to validate and store copies of the documents required for issuing or renewing driver's licenses or personal ID cards which may result in longer waits and higher fees. (Do you support or oppose this provision?)

ID4c. The Real ID Act requires non-citizens to show proof of their legal status when applying for or renewing driver's licenses or personal ID cards. (Do you support or oppose this provision?)

ID4d. The Real ID Act requires driver licenses and personal ID cards to contain a magnetic strip or a bar code that would electronically store your personal information, (such as name, birth date, social security, and address.)(Do you support or oppose this provision?)

ID4e. The Real ID Act requires states to share with each other the information collected when issuing driver's licenses or personal ID cards. (Do you support or oppose this provision?)

ID5a. Would you oppose or favor using these cards as identification for voting in federal elections?

ID5b. Would you favor or oppose using these cards as identification for banking and credit card transactions?

ID6. Overall, do you strongly approve, approve, disapprove, or strongly disapprove of the REAL ID Act passed by Congress? 


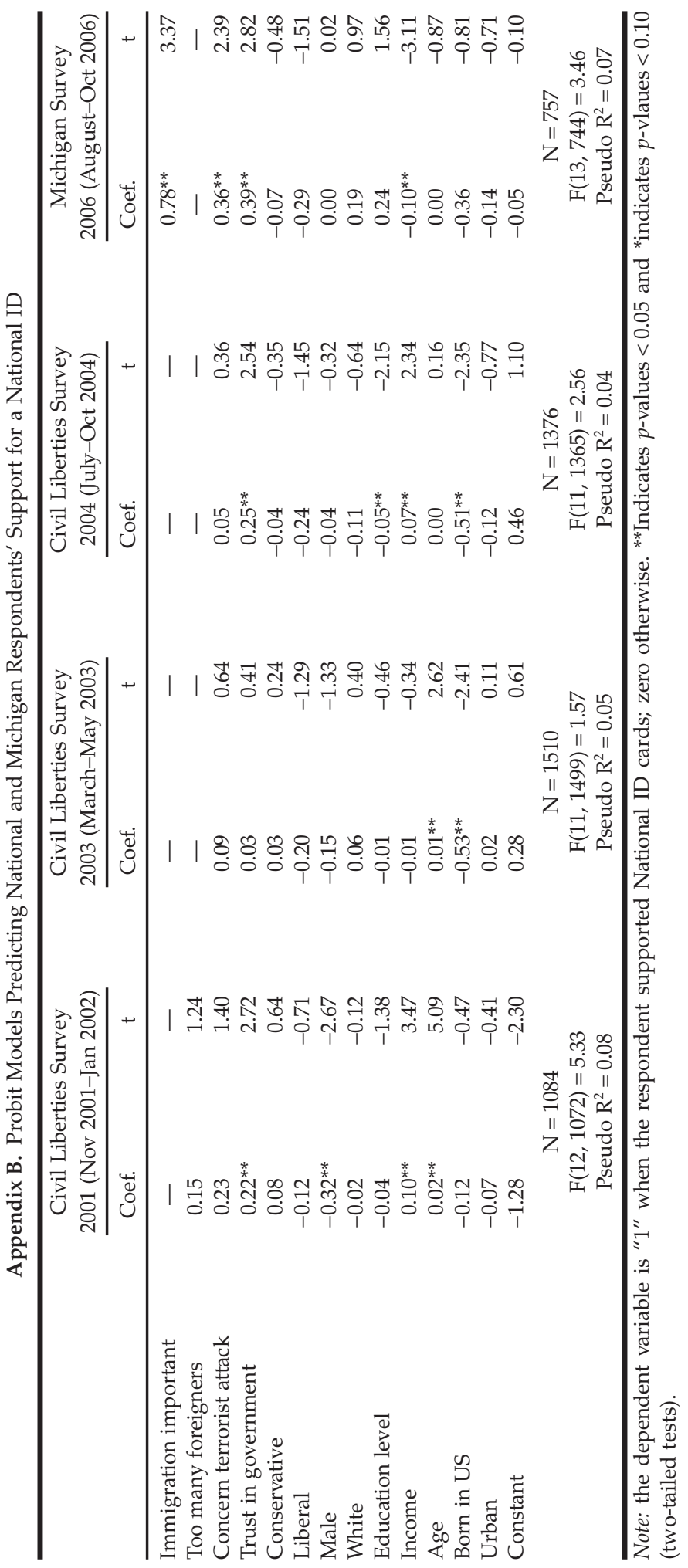

